\section{Wind Loads on Single-span Plastic Greenhouses and Solar Greenhouses}

\author{
Zai Q. Yang ${ }^{1}$, Yong X. Li ${ }^{1,3}$, Xiao P. Xue ${ }^{2}$, Chuan R. Huang ${ }^{1}$, \\ and Bo Zhang ${ }^{1}$
}

AdDITIONAL INDEX WORDs. contour, horticultural facility, wind damage, wind pressure coefficient, wind tunnel test

Summary. Wind tunnel tests were conducted in an NH-2-type wind tunnel to investigate the wind pressure coefficients and their distribution on the surfaces of a single-span plastic greenhouse and a solar greenhouse. Wind pressures at numerous points on the surfaces of the greenhouse models were simultaneously measured for various wind directions. The critical wind speeds, at which damage occurred on the surfaces of single-span plastic greenhouses and solar greenhouses, were derived. To clearly describe the wind pressure distribution on various surface zones of the greenhouses, the end surface and top surface of the plastic greenhouse and the transparent surface of the solar greenhouse were divided into nine zones, which were denoted as Zone I to Zone IX. The results were as follows: 1) At wind direction angles of $0^{\circ}$ and $45^{\circ}$, the end surface of the single-span plastic greenhouse was on the windward side, and the maximum positive wind pressure coefficient was near 1 . At wind direction angles of $90^{\circ}$ and $180^{\circ}$, the entire end surface of the singlespan plastic greenhouse was on the leeward side, and the maximum negative wind pressure coefficient was near -1 . The maximum positive wind pressure on the end surface of the single-span plastic greenhouse appeared in Zone IV at a wind direction angle of $15^{\circ}$, whereas the maximum negative pressure appeared in Zone VIII at a wind direction angle of $105^{\circ} .2$ ) Most of the wind pressure coefficients on the top surface of the plastic greenhouse were negative. The maximum positive and negative wind pressure coefficient on the top surface of the plastic greenhouse occurred in Zones I and II, respectively, at a wind direction angle of $60^{\circ} .3$ ) At a wind direction angle of $0^{\circ}$, the distribution of wind pressure coefficient contours was steady in the middle and lower zones of the transparent surface of the solar greenhouse, and the wind pressure coefficients were positive. At a wind direction angle of $90^{\circ}$, the wind pressure coefficients were negative on the transparent surface of the solar greenhouse. A maximum positive wind pressure coefficient was attained at a wind direction angle of $30^{\circ}$ in Zone IX, whereas the maximum suction force occurred in Zone VII at a wind direction angle of $135^{\circ} .4$ ) The minimum critical wind speeds required to impair the single-span plastic greenhouse and solar greenhouse were 14.5 and $18.9 \mathrm{~m} \cdot \mathrm{s}^{-1}$, respectively.

S ingle-span plastic greenhouses and solar greenhouses are frequently employed in protected horticulture in developing countries due to their simplicity and low cost. In China, the area of single-span plastic greenhouse and solar greenhouse is $4,050,000$ ha, which accounts for $90 \%$ of the total area of horticultural facilities in China. Wind damage is one of the predominant types of meteorological

This work was funded by the National special Public Sector Research [Grant No. GYHY (QX) 201006028 and Grant No. GYHY (QX) 201206024], the Science and technology support plan (social development) of Jiangsu province (NO.BE2010734), and the Academic Program Development of Jiangshu Higher Education Institutions (PARD).

${ }^{1}$ Jiangsu Key Laboratory of Agricultural Meteorology, Nanjing University of Information Science \& Technology, Nanjing, 210044, China

${ }^{2}$ Shandong Climate Center, Jinan, 250031, China

${ }^{3}$ Corresponding author. E-mail: lyxsha@nuist.edu.cn. damage to horticultural facilities. Because the structures of single-span plastic greenhouses and solar greenhouses are simple, they are more vulnerable to wind actions than the structures of modern greenhouses. Studies of wind pressure distribution on the surfaces of plastic greenhouses and solar greenhouses help to determine the minimum critical wind speed for damage to facilities and provide the scientific basis for wind damage prevention and practical greenhouse designs.

The wind tunnel test, which is an advanced technique employed in the study of wind pressure distribution on the surface of a building (Gloria et al., 2005; Zhang and Gu, 2006), is widely used in the structural design of agricultural facilities (Huang, 1991; Robertson et al., 1985). Hoxey and Richardson (1984) discussed the wind loads on full-scale film plastic-clad greenhouses. Richardson (1993) measured the wind load on a single-span film plastic-clad livestock building. Wang et al. (2008) analyzed the wind pressure distribution on a multispan plastic greenhouse, the results indicated that the wind pressure coefficients of open ventilators were distinctly bigger than the coefficients of closed ventilators, and the wind pressure distribution of greenhouse with canopy was more complicated than that of noncanopy greenhouse. Xie and Chen (2000) investigated the effects of eaves, skylights, and visor curtains on wind pressure distributions on single-span plastic greenhouses. Moriyama et al. (2008) found that the external pressure coefficient distribution was unaffected by the openings of side gable, while the internal pressure coefficients were significantly influenced by the openings of side gable. As more than two pipeframed greenhouses were often arranged in parallel, and the wind pressure distributions on the pipe houses were significantly affected by the distance between them, Moriyama et al. (2010) investigated the interaction of two or three side-by-side pipe houses on wind pressure coefficients. To date, a detailed report on wind loads on single-span plastic greenhouses and solar greenhouses in China has not been published. In this paper, the wind pressure distribution on the surfaces of typical types of single-span plastic greenhouses and solar greenhouses was studied, and the critical wind speeds for various zones on the surfaces of

\begin{tabular}{llll}
\hline $\begin{array}{l}\text { Units } \\
\text { To convert U.S. to SI, } \\
\text { multiply by }\end{array}$ & U.S. unit & SI unit & $\begin{array}{l}\text { To convert SI to U.S., } \\
\text { multiply by }\end{array}$ \\
\hline 0.3048 & $\mathrm{ft}$ & $\mathrm{m}$ & 3.2808 \\
2.54 & inch(es) & $\mathrm{cm}$ & 0.3937 \\
25.4 & inch(es) & $\mathrm{mm}$ & 0.0394 \\
16.0185 & $\mathrm{lb} / \mathrm{ft}^{3}$ & $\mathrm{~kg} \cdot \mathrm{m}^{-3}$ & 0.0624 \\
4.4482 & $\mathrm{lbf}$ & $\mathrm{N}$ & 0.2248 \\
0.4470 & $\mathrm{mph}$ & $\mathrm{m} \cdot \mathrm{s}^{-1}$ & 2.2369 \\
6894.7573 & $\mathrm{psi}$ & $\mathrm{Pa}$ & $1.4504 \times 10^{-4}$
\end{tabular}



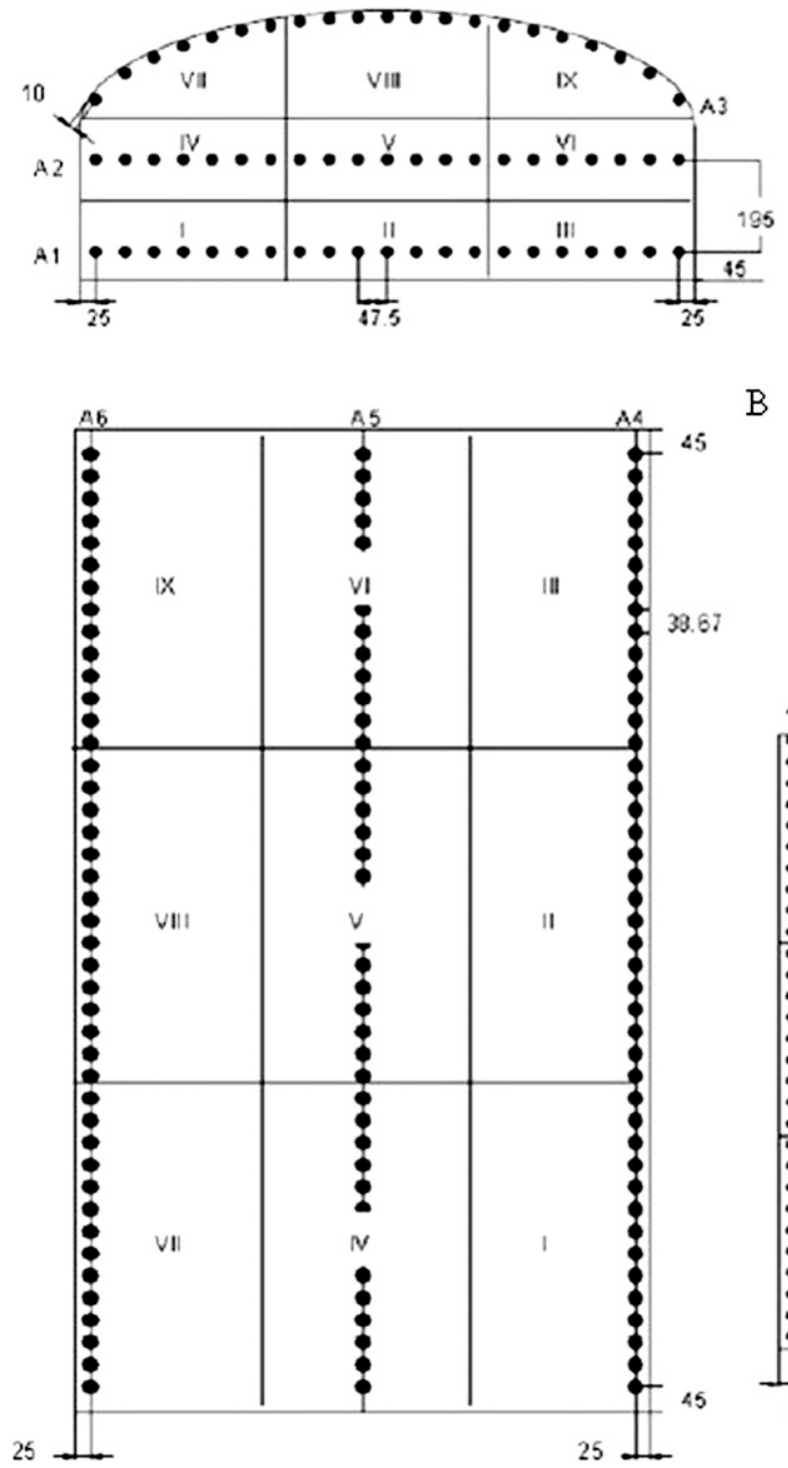

B

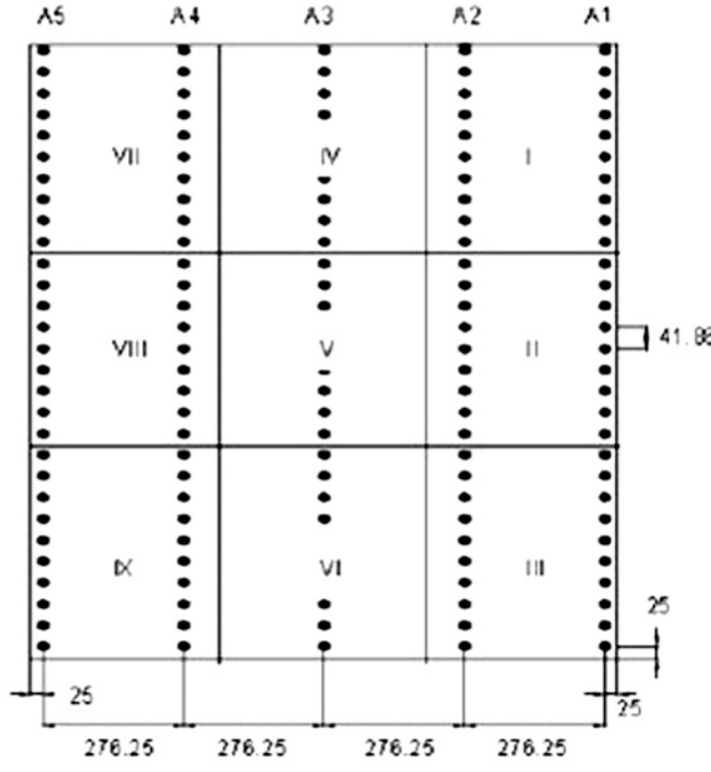

Fig. 1. Test point arrangements for the single-span plastic greenhouse model [(A) end surface and (B) top surface] and solar greenhouse model (C). (B) and (C) are horizontal expansion drawings. All dimensions are in millimeters; $1 \mathrm{~mm}=0.0394$ inch.

facilities were calculated. The results were expected to provide a scientific basis for the optimal design of agricultural facilities and the prevention of windstorm damage.

\section{Materials and methods}

The tests were conducted in Oct. 2011 in an NH-2-type singlecircumfluence low-speed wind tunnel housed at Nanjing University of Aeronautics and Astronautics, Nanjing, China. The wind tunnel was $20 \mathrm{~m}$ long, $3 \mathrm{~m}$ wide, and $2.5 \mathrm{~m}$ high, with a maximum continuously adjustable wind speed of $90 \mathrm{~m} \cdot \mathrm{s}^{-1}$. An open-country exposure was simulated in the wind tunnel. The mean velocity profile of the flow had a logarithmic law with a

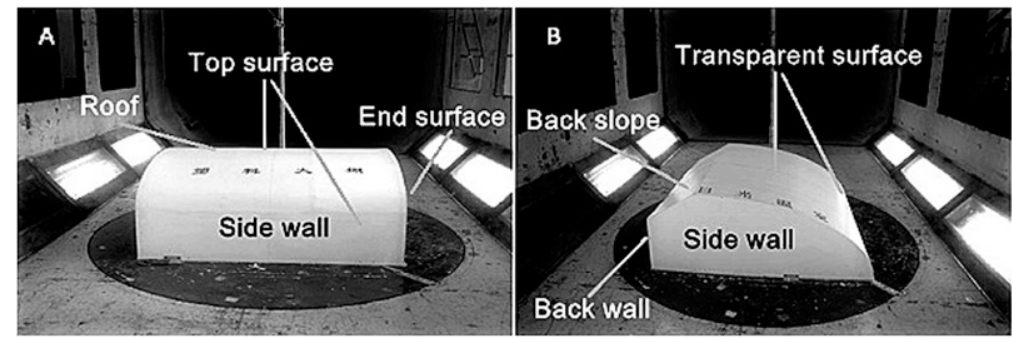

Fig. 2. Models of (A) single-span plastic greenhouse and (B) solar greenhouse for wind tunnel tests.

roughness length of $0.16 \mathrm{~cm}$. Assuming a boundary layer scale of $1: 6$, the full-scale value of roughness length was $0.96 \mathrm{~cm}$, which was within the range of full-scale measurements for flat open-country exposure (Tieleman,
2003). The heterogeneity of wind speed was less than $2 \%$ in the flow field of the test zone, the turbulence intensity was within a range of 0.10 0.14 at the ridge height of the models and the airstream deflection angles $\Delta \alpha$ 
and $\Delta \beta$ were less than $0.5^{\circ}$. The axial static pressure gradient was less than $0.004 \mathrm{~Pa} \cdot \mathrm{m}^{-1}$.

The models were made based on typical types of single-span plastic greenhouses and solar greenhouses in China, with a geometric scale of 1:6 (Fig. 1). The single-span plastic greenhouse model (Fig. 2A) contained a top height of $0.475 \mathrm{~m}$, a shoulder height of $0.250 \mathrm{~m}$, a width of $1.0 \mathrm{~m}$, and a length of $1.155 \mathrm{~m}$; the length of the top curve was one-half of an ellipse in which the semimajor axis was $0.5 \mathrm{~m}$ and the semiminor axis was $0.225 \mathrm{~m}$. The solar greenhouse model (Fig. 2B) contained a span of $1.21 \mathrm{~m}$, a ridge height of $0.45 \mathrm{~m}$, a back wall height of $0.3 \mathrm{~m}$, a back slope horizontal projection of $0.26 \mathrm{~m}$, and a length of $1.10 \mathrm{~m}$; the length of the top curve was one-fourth of an ellipse in which the semimajor axis was $0.95 \mathrm{~m}$ and the semiminor axis was $0.45 \mathrm{~m}$. The blockage ratios of the plastic greenhouse model and solar greenhouse model were $4.7 \%$ and $3.9 \%$, respectively, which did not exceed $5 \%$ of the wind tunnel cross section and was regarded as acceptable (Biagini et al., 2007).

The surfaces of the single-span plastic greenhouse were divided into the end surface and the top surface, and the top surface comprised the roof surface, the left side and the right side. For the solar greenhouse, only the transparent surface was studied because the nontransparent parts (sidewall, back wall, and back slope) of the solar greenhouse were made from brick, cement, and adobe and were much more difficult to be damaged than the transparent part. The test point arrangements for the end surface and the top surface of the singlespan plastic greenhouse model were shown in Fig. 1A and B, respectively. Three rows of test points, which were denoted as $\mathrm{Al}, \mathrm{A} 2$, and $\mathrm{A} 3$ and comprised a total of 63 test points, were arranged on the end surface. Test points from 1 to 21 were uniformly distributed on each row with an interval of $47.5 \mathrm{~mm}$. In row A3, each test point was located $10 \mathrm{~mm}$ from the top arc. Three rows of test points, which were denoted as A4, A5, and A6 and comprised a total of 129 test points, were arranged on the top surface of the single-span plastic greenhouse model. Test points 1 to 43 were uniformly arranged on each row with an interval of $38.67 \mathrm{~mm}$.
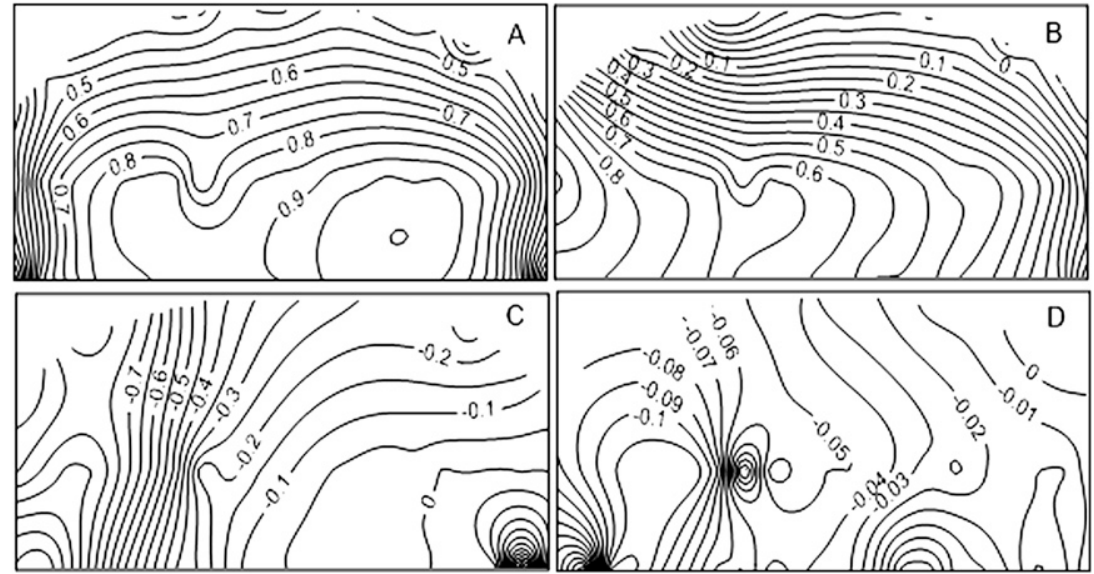

Fig. 3. Distribution of wind pressure coefficients on the end surface of the singlespan plastic greenhouse at different wind direction angles $(\mathrm{A}, \mathrm{B}, \mathrm{C}$, and $\mathrm{D}$ denote wind direction angle of $0^{\circ}, 45^{\circ}, 90^{\circ}$, and $180^{\circ}$, respectively).

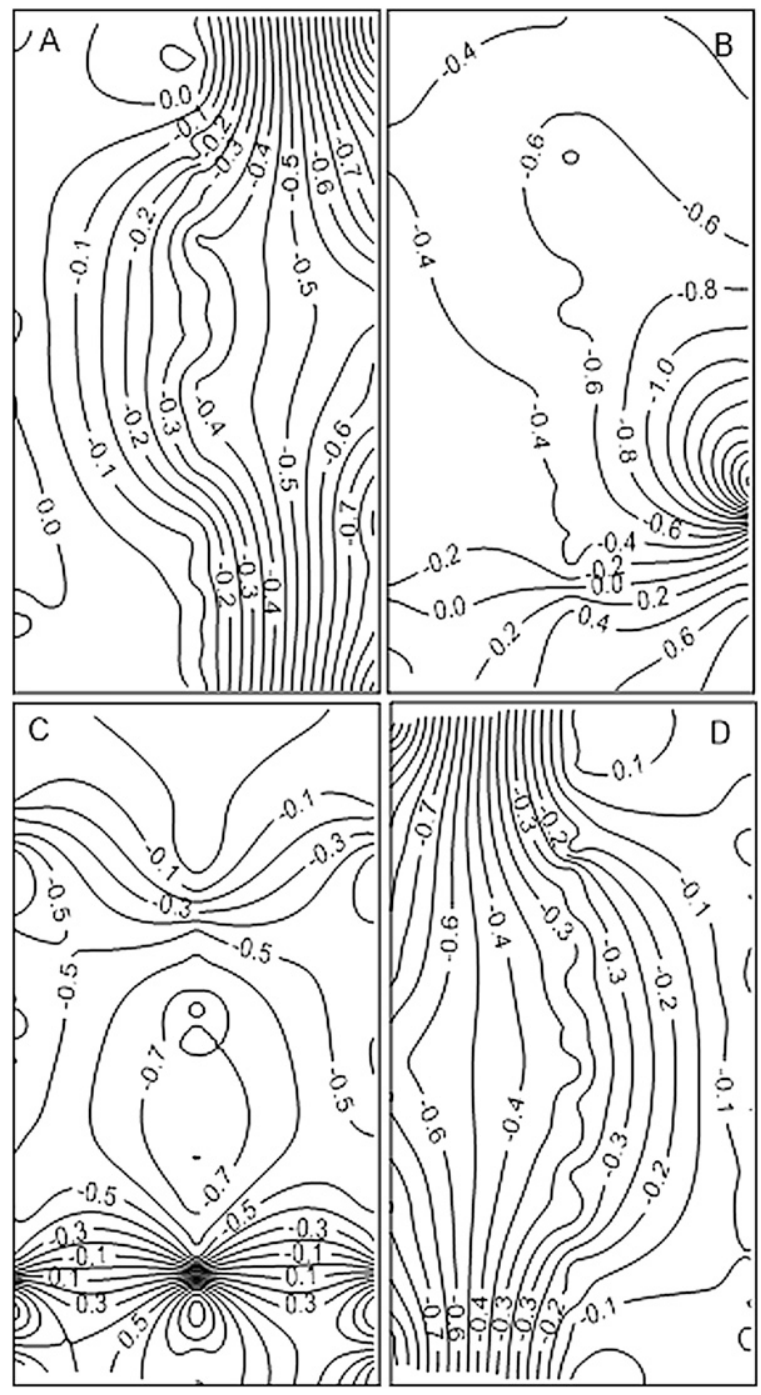

Fig. 4. Distribution of wind pressure coefficients on the top surface of the singlespan plastic greenhouse at different wind direction angles $(A, B, C$, and D denote wind direction angle of $0^{\circ}, 45^{\circ}, 90^{\circ}$, and $180^{\circ}$, respectively). 
A total of 145 test points, which were denoted by Al, A2, A3, A4, and A5 as shown in Fig. 1C, were arranged on the transparent surface of the solar greenhouse model with an interval of $276.25 \mathrm{~mm}$ between the rows. For each row, test points 1 to 29 were uniformly distributed with an interval of $41.86 \mathrm{~mm}$. To effectively analyze the wind pressure distribution on various surface zones of the greenhouse, the end surface and top surface of the plastic greenhouse model and the transparent surface of the solar greenhouse model were divided into nine zones, which were denoted with Zone I to Zone IX (Fig. 1). The test models, which were fixed on the turntable of the wind tunnel, turned to form different wind direction angles between the wind and the model. Due to the symmetry of the model, a total of 13 wind direction angles from $0^{\circ}$ to $180^{\circ}$ were tested with an interval of $15^{\circ}$ and a test wind speed of $20 \mathrm{~m} \cdot \mathrm{s}^{-1}$.

The wind pressure distribution on the model surface is typically expressed as a wind pressure coefficient, which is a dimensionless definite value and does not vary with wind speed. The wind pressure coefficient can be calculated as (Gu et al., 2010; Xie et al., 2001)

$$
C_{P_{i}}=\frac{P_{i}-P_{\infty}}{P_{0}-P_{\infty}}
$$

where $C_{P i}$ is the wind pressure coefficient (dimensionless) at the $i$ measuring point of the model, $P_{i}$ is the static pressure (Pascal) at the $i$ measuring point of the model, $P_{\infty}$ is the static pressure (Pascal) at the reference point, and $P_{0}$ is the total pressure (Pascal) at the reference point. A wind pressure coefficient greater than zero signifies positive pressure and less than zero signifies negative pressure.

In addition to Eq. [1], the wind pressure coefficient can also be calculated according to the following equation (Gu et al., 2010; Xie et al., 2001):

$$
C_{P_{i}}=\frac{W_{i}}{W}
$$

where $W_{i}$ is the actual pressure (Newtons) at the $i$ measuring point and $W$ is the inflow dynamic pressure (Newtons) at the same measuring point. According to the Bernoulli equation, the inflow dynamic pressure can be expressed as (Gloria et al., 2005; Tamura et al., 2001)

$$
W=\frac{1}{2} \rho v^{2}
$$

where $\rho$ is the air density $\left(1.25 \mathrm{~kg} \cdot \mathrm{m}^{-3}\right)$ and $\mathrm{v}$ is the wind speed (meters per second). By inserting Eq. [3] into Eq. [2], the actual pressure (Newtons) at the $i$ measuring point can be calculated as

$$
W_{i}=0.625 C_{P_{i}} \mathrm{v}^{2}
$$

According to the General Administration of Quality Supervision, Inspection and Quarantine of the People's Republic of China (2002), the maximum load for single-span plastic greenhouses and solar greenhouses are 196 and $313.6 \mathrm{~N} \cdot \mathrm{m}^{-2}$, respectively. Based on Eq. [4], the critical wind speed can be calculated for various zones on surfaces of facilities at different wind direction angles.

The wind pressure contours were created using Suffer 11.

\section{Results and discussion}

The contours that depict the distribution of wind pressure coefficients on the end surface of the singlespan plastic greenhouse at different wind direction angles were shown in Fig. 3. At wind direction angles of $0^{\circ}$ and $45^{\circ}$ (Fig. $3 \mathrm{~A}$ and $\mathrm{B}$ ), the end surface of the plastic greenhouse was on the windward side. The contours at the edge of the windward zones were dense, which indicated a dramatic change in wind pressure coefficients, and the maximum positive wind pressure coefficient was $\approx 1$. At wind direction angles of $90^{\circ}$ and $180^{\circ}$ (Fig. 3C and D), the end surface of the plastic greenhouse was in the leeward zone, where the contour distribution of the wind pressure coefficients were relatively sparse and the maximum negative wind pressure coefficient was near zero.

The contours that represent the distribution of the wind pressure coefficients on the top surface of the single-span plastic greenhouse at different wind direction angles are shown in Fig. 4. At wind direction angles of $0^{\circ}$ and $180^{\circ}$ (Fig. 4A and D), the top surface of the plastic greenhouse was in the leeward zone, where all wind pressure coefficients were negative and the contour distribution was uniform; these results indicated a smooth variation in wind pressure. When the wind direction angles were $45^{\circ}$ and $90^{\circ}$ (Fig. $4 \mathrm{~B}$ and $\mathrm{C})$, the wind pressure coefficients were positive in the windward zones on the top surface of the single-span plastic

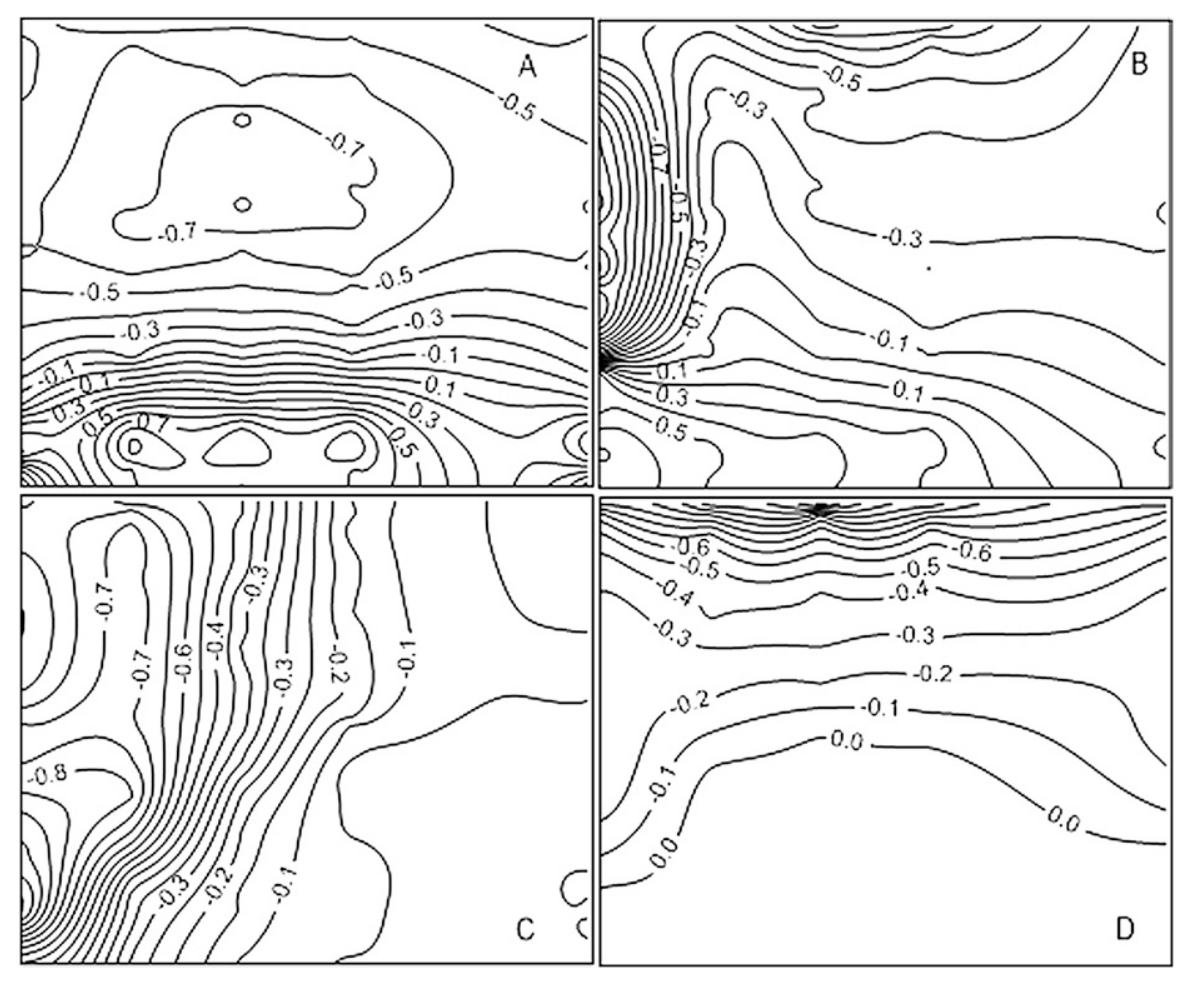

Fig. 5. Distribution of wind pressure coefficients on the transparent surface of the solar greenhouse at different wind direction angles $(\mathrm{A}, \mathrm{B}, \mathrm{C}$, and $\mathrm{D}$ denote wind direction angle of $0^{\circ}, 45^{\circ}, 90^{\circ}$, and $180^{\circ}$, respectively). 
greenhouse. High negative pressure zones appeared at the edge of the windward zone and the roof ridge of the single-span plastic greenhouse, with significant variation in the gradients of the wind pressure coefficients.

In Fig. 5, the contours of the distribution of the wind pressure coefficients on the transparent surface of the solar greenhouse were depicted for different wind direction angles. The figure demonstrated that at a wind direction angle of $0^{\circ}$ (Fig. $5 \mathrm{~A}$ ), the front zone of the transparent surface of the solar greenhouse was in the windward zone, the wind pressure coefficients were all positive and the contours of the distributions were uniform. The variation in wind pressure coefficients was smooth in the rear zones of the transparent surface of the solar greenhouse, and the wind pressure coefficients were negative. At a wind direction angle of $45^{\circ}$ (Fig. $5 \mathrm{~B})$, the wind pressure coefficients were positive on the windward side of the transparent surface of the solar greenhouse. A high negative pressure zone formed at the junction site of the back slope and the transparent surface, and a large variation in the gradient of wind pressure coefficient, which was related to the flow separation of wind, was evident. At a wind direction angle of $90^{\circ}$ (Fig. 5C), the wind pressure coefficients on the top surface of the solar greenhouse were negative because the airflow was blocked by the back slope and back wall. When the wind direction angle was $180^{\circ}$ (Fig. 5D), the airflow passed through the side wall and the wind pressure coefficients on the transparent surface of the solar greenhouse were negative.

The average value of wind pressure coefficients for all test points in each zone represented the average wind pressure coefficient within the zone. Figure 6A displayed the variation in wind pressure coefficients for various zones on the end surface of the single-span plastic greenhouse. When the wind direction angle changed from $0^{\circ}$ to $180^{\circ}$, the wind pressure coefficients in the nine zones on the end surface exhibited a consistent trend, which ranged from positive to negative values. After reaching a maximum negative pressure, the suction force gradually weakened to zero at a wind direction angle of $180^{\circ}$. As the wind direction angle was rotated above $90^{\circ}$, the end surface of the plastic
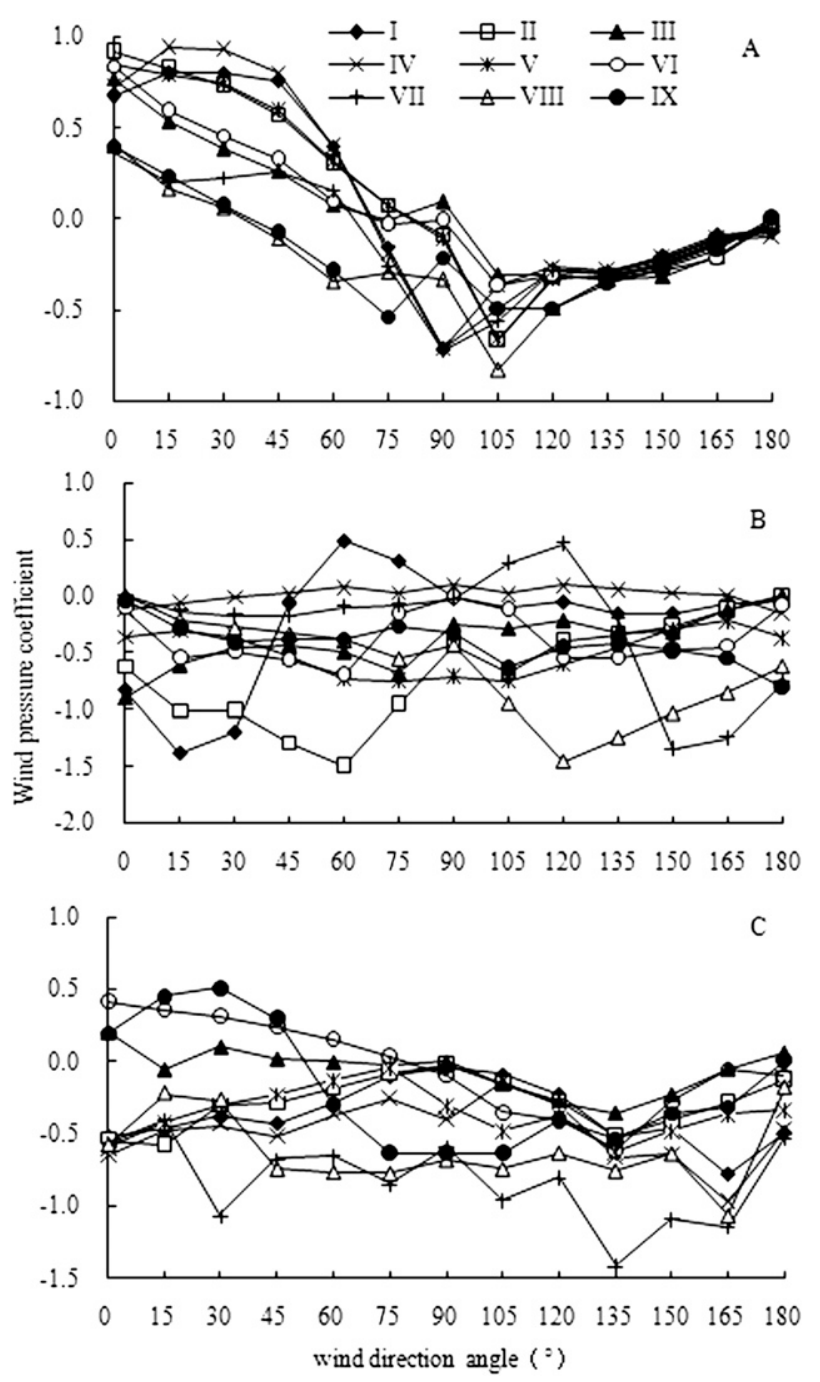

Fig. 6. Tendency for variation in the wind pressure coefficients with variation in wind direction angles $(\mathrm{A}, \mathrm{B}$, and $\mathrm{C}$ denote the end surface of the single-span plastic greenhouse, the top surface of the single-span plastic greenhouse, and the transparent surface of the solar greenhouse, respectively).

greenhouse changed from windward to leeward, and the wind pressure coefficients in various zones yielded negative values. At a wind direction angle of $135^{\circ}$, the wind pressure coefficients for various zones on the end surface of the plastic greenhouse were similar. When the wind direction angle was $180^{\circ}$, the wind had minimal effect on the end surface of the single-span plastic greenhouse. A maximum positive wind pressure of 0.94 appeared in Zone IV at a wind direction angle of $15^{\circ}$, whereas a maximum negative pressure of -0.84 appeared in the VIII zone at a wind direction angle of $105^{\circ}$. Zone IV was the most easily damaged zone on the end surface of the single-span plastic greenhouse.

When the wind direction angle changed from $0^{\circ}$ to $180^{\circ}$, the wind pressure coefficients in Zones I, IV, and VII on the top surface (Fig. 6B) of the single-span plastic greenhouse changed from negative to positive and then from positive to negative, but the wind pressure coefficients in Zones II, III, V, VI, VIII, and IX were always negative. This trend was because rotating the wind direction angle from $0^{\circ}$ to $180^{\circ}$ caused Zones I, IV, and VII to appear on the windward side in sequence; however, Zones II, III, V, VI, VIII, and IX were always present on the leeward side during this process. Due to the symmetry of the single-span plastic greenhouse, the variations in wind pressure coefficients exhibited opposite trends with increases in wind direction angles between Zones I and VII, Zones II and VIII, and Zones III 
Table 1. Maximum wind pressure coefficients and the corresponding critical wind speeds for damage to various zones of single-span plastic greenhouses.

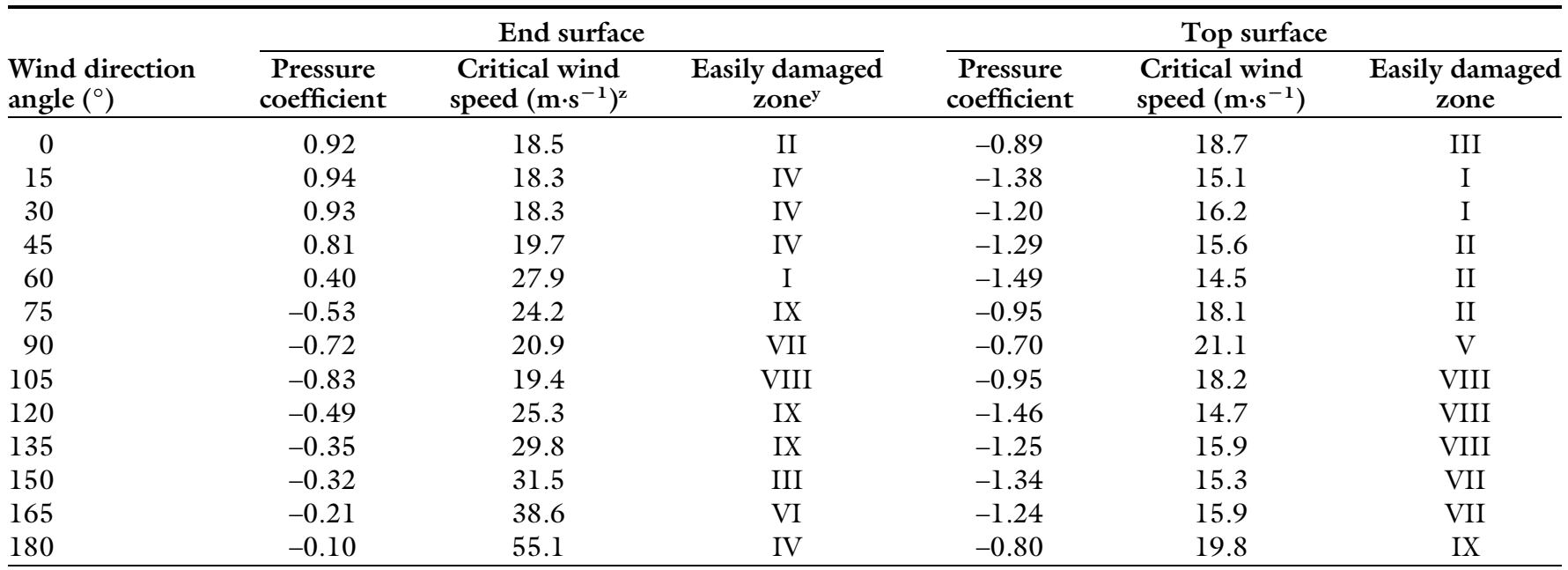

${ }^{\mathrm{z}} 1 \mathrm{~m} \cdot \mathrm{s}^{-1}=2.2369 \mathrm{mph}$.

'Zones depicted in Fig. 1.

and IX, respectively. The maximum positive wind pressure coefficient was near 0.5 , which occurred in Zone I when the wind direction angle was $60^{\circ}$. The maximum suction appeared at a wind direction angle of $60^{\circ}$ in Zone II, where the wind pressure coefficient was near -1.5 . Zone II was the most easily damaged zone on the top surface of the single-span plastic greenhouse.

When the wind direction angle changed from $0^{\circ}$ to $180^{\circ}$, the wind pressure coefficients for Zones III, VI, and IX of the transparent surface of the solar greenhouse changed from positive to negative (Fig. 6C), whereas the wind pressure coefficients in Zones I, II, IV, V, VII, and VIII were all negative during the process. As the wind direction angle rotated from $0^{\circ}$ to $180^{\circ}$, Zones III, VI, and IX were present on the windward side and Zones I, II, IV, V, VII, and VIII were present on the leeward side. The wind pressure coefficients varied slightly with the variation in wind direction angle in Zones III and VI. The maximum positive wind pressure coefficient occurred at a wind direction angle of $30^{\circ}$ in Zone IX. The maximum suction force appeared in Zone VII at a wind direction angle of $135^{\circ}$, which was near -1.41 . Zone VII was the most easily damaged zone in the solar greenhouse.

Tables 1 and 2 show the critical wind speeds in various zones of the surfaces of facilities at different wind direction angles. The wind suction force on Zone II at a wind direction

Table 2. Maximum wind pressure coefficients and the corresponding critical wind speeds for damage to various zones of solar greenhouses.

\begin{tabular}{cccc}
\hline $\begin{array}{l}\text { Wind direction } \\
\text { angle }\left({ }^{\circ}\right)\end{array}$ & $\begin{array}{c}\text { Pressure } \\
\text { coefficient }\end{array}$ & $\begin{array}{c}\text { Critical wind } \\
\text { speed }\left(\mathbf{m} \cdot \mathbf{s}^{-\mathbf{1}}\right)^{\mathbf{z}}\end{array}$ & $\begin{array}{c}\text { Easily damaged } \\
\text { zone }^{\mathbf{y}}\end{array}$ \\
\hline 0 & -0.64 & 28.0 & IV \\
15 & -0.57 & 29.8 & IX \\
30 & -1.07 & 21.7 & VII \\
45 & -0.74 & 26.0 & VII \\
60 & -0.76 & 25.7 & VIII \\
75 & -0.85 & 24.3 & VII \\
90 & -0.68 & 27.2 & VIII \\
105 & -0.96 & 22.9 & VII \\
120 & -0.80 & 25.0 & VII \\
135 & -1.41 & 18.9 & VII \\
150 & -1.09 & 21.4 & VII \\
165 & -1.14 & 21.0 & VII \\
180 & -0.53 & 30.8 & VII \\
\hline
\end{tabular}

${ }^{\mathrm{z}} 1 \mathrm{~m} \cdot \mathrm{s}^{-1}=2.2369 \mathrm{mph}$.

'Zones depicted in Fig. 1 .

angle of $60^{\circ}$ was the greatest among all the zones on the top surface of the single-span plastic greenhouse, and the corresponding minimum critical wind speed for damage to the top surface of the single-span plastic greenhouse was $14.5 \mathrm{~m} \cdot \mathrm{s}^{-1}$. Whereas the wind pressure on Zone IV at wind direction angles of $15^{\circ}$ was the greatest among all the zones on the end surface of the single-span plastic greenhouse, the corresponding minimum critical wind speed for damage to the end surface was $18.3 \mathrm{~m} \cdot \mathrm{s}^{-1}$. Thus, the top surface of a single-span plastic greenhouse was more susceptible to wind damage than the end surface. For the solar greenhouse, at a wind direction angle of $135^{\circ}$, a maximum wind suction force and a minimum critical wind speed of $18.9 \mathrm{~m} \cdot \mathrm{s}^{-1}$, which can cause damage to the solar greenhouse, was attained in Zone VII. A single-span plastic greenhouse was more vulnerable to wind actions than a solar greenhouse because the plastic-film cladding of a single-span plastic greenhouse was usually simply wrapped around the arch from one side to the other and was anchored only at the ground level, with no intermediate fixings around the circumference of the arch (Robertson et al., 2002). Being supported by back wall and sidewall, a solar greenhouse was able to bear more wind loads. However, the minimum critical wind speed derived in this article was a theoretical value without regarding the aeroelasticity, and has 
not been validated due to lack of statistical details. Future research will be focused on the correction and validation of minimum critical wind speed for damage to horticultural facilities.

Limited by the experimental facilities, the number of measuring points in the wind tunnel test is always insufficient, which may affect the accuracy of the results. With advances in computer technologies, computational fluid dynamics (CFD) have been used to compensate for insufficient wind tunnel test data (Mistriotis and Briassoulis, 2002). Based on wind tunnel tests, the use of CFD technology can help to accurately obtaining pressure distributions on the surfaces of facilities. Therefore, combining wind tunnel tests with CFD technology to determine pressure distributions on facilities is an important direction for the future study of surface wind load on greenhouses.

\section{Literature cited}

Biagini, P., C. Borri, and L. Facchini. 2007. Wind response of large roofs stadiums and arena. J. Wind Eng. Ind. Aerodyn. 95:871-877.

General Administration of Quality Supervision, Inspection and Quarantine of the People's Republic of China. 2002. Greenhouse structure design load. GB/T 18622-2002.

Gloria, G.M., A. Rodrigues, and M. Pedro. 2005. Experimental and numerical study of wind pressures on irregular-plan shapes. J. Wind Eng. Ind. Aerodyn. 93: 74l-756.

Gu, M., Y.L. Zhao, Q. Huang, P. Huang, Y. Quan, and Z.N. Xie. 2010. Wind tunnel test and numerical simulation of mean wind pressures on roof of low-rise buildings. Acta Aerodynamics Sinica 28:82-87.

Hoxey, R.P. and G.M. Richardson. 1984. Measurements of wind loads on full-scale film plastic clad greenhouses. J. Wind Eng. Ind. Aerodyn. 16:57-83.

Huang, Z.Q. 1991. The wind tunnel testing for agro-space plant. Expt. Measurements Fluid Mechanics 5:1-7.

Mistriotis, A. and D. Briassoulis. 2002. Numerical estimation of the internal and external aerodynamic coefficients of a tunnel greenhouse structure with openings. Comput. Electron. Agr. 34:191-205.

Moriyama, H., S. Sase, Y. Uematsu, and T. Yamaguchi. 2008. Wind pressure coefficient of a pipe-framed greenhouse and influence of the side gable openings using a wind tunnel. J. Soc. Agr. Structures Jpn. 3:237-248.

Moriyama, H., S. Sase, Y. Uematsu, and T. Yamaguchi. 2010. Wind tunnel study of the interaction of two or three side-byside pipe-framed greenhouses on wind pressure coefficients. Trans. Amer. Soc. Agr. Biol. Eng. 53:585-592.

Richardson, G.M. 1993. Full-scale wind load measurements on a single-span film plastic-clad livestock building. J. Agr. Eng. Res. 55:251-264.

Robertson, A.P., Ph. Rouxb, J. Gratraudb, G. Scarasciac, S. Castellanoc, M. Dufresne de Vireld, and P. Palier. 2002. Wind pressures on permeably and impermeablyclad structures. J. Wind Eng. Ind. Aerodyn. 90:461-474.

Robertson, A.P., R. Hoxey, and P. Moran. 1985. A full-scale study of wind loads on agricultural ridged canopy roof structures and proposals for design. J. Wind Eng. Ind. Aerodyn. 21:167-205.

Tamura, Y., H. Kikuchi, and K. Hibi. 2001. Extreme wind pressure distributions on low-rise building models. J. Wind Eng. Ind. Aerodyn. 89:16351646.

Tieleman, H.W. 2003. Wind tunnel simulation of wind loading on low-rise structures: A review. J. Wind Eng. Ind. Aerodyn. 91:1627-1649.

Wang, J., W.M. Ding, and Y.F. Wu. 2008. Wind tunnel test of wind pressure distribution on mutual insert multi-greenhouse roof. Trans. Chinese Soc. Agr. Eng. 24: 230-234.

Xie, X.Y. and K. Chen. 2000. Simulation test of wind load characteristics of south China type single-span plastic greenhouse. Trans. Chinese Soc. Agr. Eng. 16: 90-94.

Xie, Z.N., Z.H. Ni, and B.Q. Shi. 2001. Experimental investigation on characteristics of wind load on large span roof. J. Building Structures 22:23-28

Zhang, A. and M. Gu. 2006. Wind tunnel tests and numerical simulation of wind pressures on buildings in staggered arrangement. J. Wind Eng. Ind. Aerodyn. 11:2067-2079. 